Análisis judicial de la naturaleza jurídica de la relación contractual en el trabajo en plataformas de reparto urbano.

A propósito de sentencia del Tribunal Supremo de 25 de septiembre de 2020

(núm. 805/2020; rec. 4746/2019).

JOSÉ MARÍA RUZ LÓPEZ*

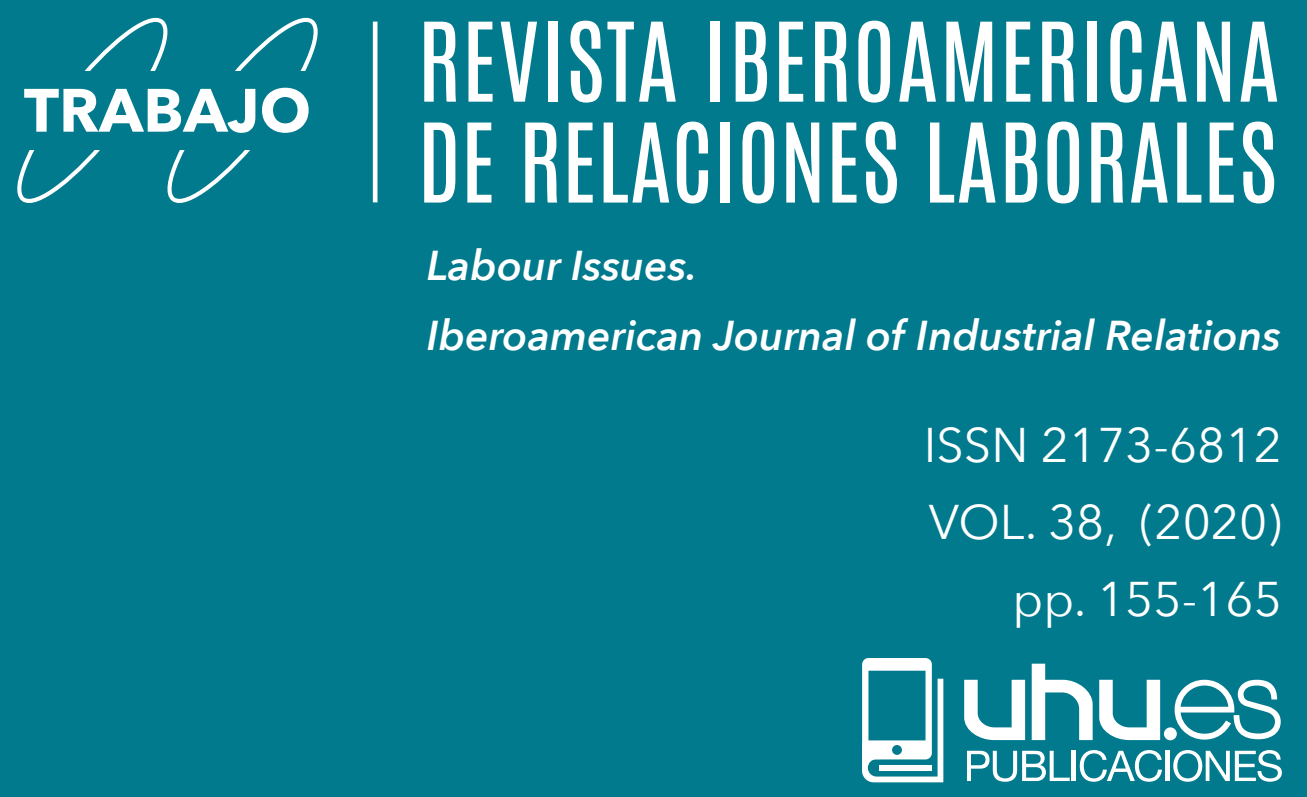




\section{FeCHA RECEPCIÓN:}

2020-06-14

FECHA REVISIÓN:

2020-06-25

\section{RESUMEN:}

Las nuevas formas de trabajo surgidas a raíz de la economía colaborativa, o, mejor dicho, a raíz de movimientos derivados de la misma han reavivado el clásico debate sobre las fronteras entre el trabajador por cuenta ajena por cuenta propia. Desde el ámbito laboral es necesario cuestionar si esta nueva realidad como para escapar de los márgenes actuales del Derecho del Trabajo, o si, por el contrario, es un nuevo intento -entre otros muchos más- de «huida» fraudulenta de esta disciplina.

Es considerable la cantidad de resoluciones administrativas y judiciales sobre la naturaleza jurídica de estas relaciones contractuales, ncluyendo la reciente sentencia del Tribunal Supremo. Las empresas de reparto urbano han protagonizado preponderantemente estos conflictos. El análisis de dichos pronunciamientos constituye el núcleo de este trabajo.

\section{Palabras clave}

Trabajo en plataformas, relación laboral, trabajo por cuenta ajena, análisis judicial.

\section{FECHA ACEPTACIÓN:}

2020-10-30

FECHA PUBLICACIÓN:

2020-12-05

Abstract

New forms of employment issued from sharing economy, or even better, issued from movements based on sharing economy have brought the classical debate about the difference between employees and self-employed workers back. From a labour point of view, it is necessary to wonder whether this new reality is rupturist enough to avoid labour regulations, is rupturist enough to avoid labour regulations, or whether, on the contrary, may be a fraudulent the Labour Law.

The amount of administrative and judicial resolutions about the legal status of this new contractual relations is now starting to be the Supreme Court. Urban delivery companie have led most of these conflicts. The analysi of these resolutions would be the core of this research

\section{KeYWORDS}

Citizen's income; social insertion; minimum insertion income; relative poverty.

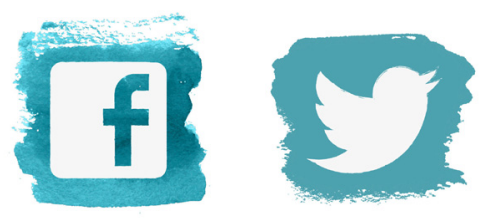




\section{ANÁLISIS JUDICIAL DE LA NATURALEZA JURÍDICA DE LA RELACIÓN CONTRACTUAL EN EL TRABAJO EN PLATAFORMAS DE REPARTO URBANO.}

\section{A propósito de sentencia del Tribunal Supremo de 25 de septiembre de 2020 (núm. 805/2020; rec. 4746/2019).}

\section{Introducción}

Siguiendo las palabras de Alonso Olea: "la realidad social sobre la que el Derecho de Trabajo descansa no es el trabajo en general, sino un tipo muy especial y muy característico de trabajo" 1

Desde el nacimiento de nuestra disciplina, surge el reto de decidir qué tipo de trabajo es el objeto de nuestra materia. Esta discusión no es novedosa, ni tampoco baladí Determinar el objeto del Derecho del Trabajo, supone dibujar los contornos de nuestra disciplina, decidiendo así las situaciones que merecen una especial protección. Como es previsible, este hecho no es propio de España, sino que cada sistema jurídico mínimamente desarrollado ha debido resolver este interrogante.

No obstante, estas tensiones no son lineales en el tiempo. Cuando se produce una transformación tecnológica, y, por ende, un cambio en las formas de trabajo, las fronteras de nuestra materia se ponen aún más en cuestión. Hemos de recordar que el Derecho del Trabajo, tal y como lo conocemos hoy en día, se constituyó como disciplina especial o autónoma a raíz de la Revolución Industrial. Teniendo esto en cuenta, no sorprende que acontecimientos económicos y tecnológicos tengan un impacto directo en esta disciplina. Las «huidas» y «recuperaciones» del Derecho del Trabajo forman parte de su idiosincrasia, marcando el ritmo de su evolución.

Este interrogante tradicional se ha vuelto a poner de manifiesto de la mano de las transformaciones ligadas a la economía colaborativa. El presente artículo analizará si estas nuevas formas de prestar servicios encajan en el "trabajo objeto del Derecho de Trabajo", continuando con la terminología empleada por Alonso Olea.

1. Alonso Olea, M. (1994). Introducción al Derecho del Trabajo. Civitas, pág. 38.

\section{Delimitación del objeto de estudio}

Como punto de partida, es necesario realizar un breve examen sobre el material objeto de nuestro análisis. El impacto de los últimos avances tecnológicos en las relaciones laborales es un ámbito inabarcable. Por ello, en el presente trabajo centraremos nuestra atención en la vertiente laboral de la economía colaborativa, o, mejor dicho, los modelos surgidos a raíz de esta, pero que ya poco tienen que ver con intercambios colaborativos strictu sensu. Sin ánimo de profundizar demasiado en la cuestión, la economía colaborativa, en su origen, estaba basada en intercambios sin ánimo de lucro entre particulares. No obstante, sobre la base de este modelo, las empresas comenzaron a utilizar esta nueva tecnología -las plataformas digitales- con el objetivo de prestar servicios de forma profesional. Aunque dichas empresas se afanen en demostrar lo contrario, sus modelos de negocio ya nada tienen que ver con los originarios intercambios sin ánimo de lucro entre particulares ${ }^{2}$. De ahí que, para analizar el uso profesional de la plataforma, sea más correcto sustituir el término economía colaborativa por el de economía en plataformas o trabajo en plataformas. En este estudio nos centraremos en este último fenómeno, puesto que es más interesante a efectos laborales.

A su vez, el trabajo en plataformas presenta dos vertientes: "crowdwork" y "work ondemand vía apps" taformas online, "se trabaja desde el ciberespacio, sin que haya contacto físico entre prestador y cliente" mientras que en el work on-demand via apps", denominado trabajo en plataformas offline, "la plataforma requiere que el prestador del servicio lo realice presencialmente"4. El presente artículo versa sobre el trabajo en plataformas offline. La mayoría de las resoluciones judiciales y administrativas abordan controversias de esta naturaleza. Igualmente, la doctrina iuslaboralista ha centrado su atención sobre este modelo. Aunque es cierto que, en la actualidad, están surgiendo interesantes debates en foros doctrinales sobre la vertiente online del trabajo plataformas ${ }^{5}$

2. Desde la doctrina se ha venido advirtiendo de este hecho. Según Cruz Villalón, esta expresión es "claramente distorsionadora de la realidad que pretende describir". Cruz Villalón, J. (2018). Las transformaciones de las relaciones laborales ante la digitalización de la economía". Temas laborales, núm. 138/2018, págs. 23 y 24

3. De Stefano, V. (2016) The rise of the «just-in-time workforde»: On-demand work, crowdwork and labour protection in the «gig-economy»; Conditions of work and employment, ILO (no. 71), pág. 2.

4. Gorelli Hernández, J. (2019). Indicios de la moralidad en el trabajo a través de plataformas (crowdsourcing offline)". Revista de Derecho Social, núm. 86, pág. 40

5. Gines y Fabrelals, A. (2016). Crowdsourcing sites y nuevas formas de trabajo. El caso de Amazon Mechanical Turk. Revista Derecho Social y Empresa; núm. 6, diciembre; De Las Heras García, A y Lanzadera Arencibia, E. (2019). El trabajo en plataformas digitales, puro... y duro. Un análisis desde los factores de riesgo laboral. Revista de Trabajo y Seguridad Social, CEF, número extraordinario 2019 
El trabajo en plataformas offline aglutina gran diversidad de prestaciones, entre ellas, guías turísticos, conducción de pasajeros, reparto urbano. Estas últimas plataformas -en nuestro país Glovo, Deliveroo y Take Eat Easy- son las que han protagonizado mayor número de resoluciones tanto judiciales como de la Inspección de Trabajo y de la Seguridad Social (ITSS, en adelante). Por esta razón, basamos nuestro estudio en este modelo de negocio.

De entre todas las posibles discusiones surgidas como consecuencia de esta realidad centraremos nuestra atención en la naturaleza jurídica de la relación contractual. Nuestra hipótesis es comprobar si estas nuevas formas de trabajo suponen una verdadera «huida» del Derecho del Trabajo.

\section{Análisis transversal sobre resoluciones administrativas y judiciales}

Teniendo en cuenta lo hasta ahora planteado, podremos abordar el núcleo de este estudio: un análisis trasversal del conjunto de resoluciones sobre esta realidad.

\subsection{Estado de la cuestión}

Aproximadamente a partir de 2015, la doctrina iuslaboralista española comienza a reflexionar sobre estas nuevas formas de prestar servicios. A finales de 2017, la ITSS emite la primera acta que declara la laboralidad de los riders. Tenemos que esperar hasta 2018 para que, en concordancia con el principio de justicia rogada, los Juzgados de los Socia empiecen a dirimir conflictos de estas características. En 2019 se dictan numerosas sentencias sobre esta cuestión, entre las que empiezan a aparecer los primeros pronunciamientos de Tribunales Superiores de Justicia. Finalmente, en 2020, tras la publicación de numerosas sentencias tanto de Juzgados de lo Social como de Tribunales Superiores de Justicia, el Tribunal Supremo (TS, en lo que sigue) dicta su sentencia de 25 de septiembre de 2020 (núm. 805/2020; rec. 4746/2019) sobre la controversia analizada mediante la resolución de un recurso de casación para la unificación de doctrina.

Desde la esfera comunitaria, la sentencia del TJUE de 20 de diciembre de 2017, asunto C-434/15, sobre el caso Uber, supuso un pilar fundamental para el estudio del trabajo en plataformas. Aunque no es una sentencia del ámbito laboral, en aras de discernir si la plataforma Uber era una mera intermediaria o prestaba un servicio subyacente, el TJUE comenzó a examinar elementos que posteriormente han sido relevantes para el análisis laboral en sede judicial.

Volviendo al ámbito nacional, debemos pues comenzar recordando que respecto al signo de los pronunciamientos no existía una tendencia clara entre los Juzgados de lo Social. No ocurría lo mismo entre las sentencias de los Tribunales Superiores de Justicia que salvo en una ocasión (precisamente la que es recurrida en casación) han defendido la laboralidad de la relación contractual. Esa misma posición defiende finalmente el TS mediante la resolución que aquí comentamos.

La metodología empleada en este estudio está inspirada en la jurisprudencia clásica sobre relaciones de laboralidad. En reiteradas ocasiones, el TS, ha establecido que una relación contractual es de naturaleza laboral cuando se constata la existencia de las notas de subordinación/dependencia y ajenidad. Ambos son conceptos abstractos por lo que su presencia en el caso concreto ha de ser valorada mediante la ponderación de indicios, tanto a favor como en contra.

De ahí que la sistemática de este estudio consista en analizar el uso de tal teoría de indicios de ajenidad y subordinación (art. 1 LET) en las resoluciones previas sobre este tema concreto y contrastar estos antecedentes con la posición y argumentación manejados en la señalada sentencia del TS de septiembre de 2020.

\subsection{Indicios de subordinación: entre la libertad del repartidor y el poder empresarial}

La supuesta libertad del repartidor para elegir horarios, así como, para rechazar pedidos es un argumento reiterado entre las voces que abogan por la naturaleza mercantil de la relación entre plataformas y repartidores. Estos indicios, ambos contrarios a la subordinación, han sido incluidos en todas las sentencias que dictaminan la no laboralidad del rider.

La anterior hipótesis ha sido ampliamente refutada, tanto desde la ITSS, como desde numerosos Juzgados de lo Social y Tribunales Superiores de Justicia ${ }^{6}$. En esta línea se sitúa la reciente sentencia del TS, la cual analiza este indicio con especial detenimiento -siendo el que mayor atención recibe-. Como así establece el TS en el fundamento jurídico $18^{\circ}$, ordinal $2^{\circ}$, la libertad del repartidor para elegir horarios y rechazar pedidos no es realmente tal, pues está fuertemente condicionada por los elementos concurrentes. Concluye así, que si bien teóricamente el rider puede rechazar pedidos sin penalización alguna lo cierto es que el hecho de rechazar un pedido acaba disminuyendo su puntuación en el sistema de valoración, lo que supone una reducción de pedidos asignados y, por tanto, de retribución. Y, por otro

6. Entre otros, Acta ITSS Valencia sobre Deliveroo de diciembre de 2017, SJS n5 de Valencia, de 10 de junio de 2019 (núm. 197/2019; rec. 371/2018) (F.J. 2º), SJS nº19 de Madrid, de 22 de julio de 2019 (núm. 188/2019) (F.J. 6º quinto párrafo), SJS nº3 de Barcelona, de 18 de noviembre de 2019 (núm. 325/2019) (F.J. 4 , ordinal 24, STSJ Cataluña de 21 de febrero de 2020 (núm. 1034/2020; rec. 5613/2019) (F.J. $7^{\circ}$ ). 
lado, aunque teóricamente el repartidor también puede elegir cuando trabajar, no puede desconocerse que, si no está disponible en las horas con más demanda, su puntuación disminuye y con ello su retribución. Como podemos apreciar, esta argumentación coincide en gran medida con las resoluciones de tribunales inferiores los cuales ya había llegado a demostrar que la elección de horarios debe llevarse a cabo dentro de las franjas previamente establecidas por la plataforma en función del sistema de valoración, lo que condiciona aún más la supuesta libertad del rider ${ }^{7}$.

En resumidas cuentas, aunque formalmente el repartidor pueda elegir horarios y rechazar pedidos, en la práctica, estas acciones no son completamente libres dado que acarrean una serie de consecuencias económicas negativas, articuladas mediante el sistema de valoración.

Es interesante observar que no es la primera vez que el TS plantea esta idea. En la STS de 16 de noviembre de 2017 (núm. 902/2017; rec. 2806/2015), relativa al llamado caso traductores, el TS afirmó que en casos como el que comentamos, simplemente "parece" que existe libertad, no que realmente así sea, puesto que "corre el riesgo de que no se vuelva a llamar"8.

El grado de libertad del repartidor durante la ejecución del servicio es otro importante indicio a la hora de valorar su nivel de dependencia. Recuérdese que varias sentencias de los tribunales inferiores habían incluso declarado que los riders cuentan con el "dominio completo de su actividad"9. A su vez, para avalar ta conclusión, recordaban que la figura del TRADE admite la posibilidad de "proporcionar ciertas indicaciones" por parte del cliente ${ }^{10}$.

En contraposición, numerosos pronunciamientos, tanto administrativos como judiciales, han confrontado la idea anterior, demostrando la existencia de un amplio abanico de instrucciones impuestas por la empresa en relación con la prestación

7. Como podemos comprobar en SJS nº de Valencia, de 1 de junio de 2018 (núm. 244/2018) (F.J 2º, quinto párrafo), SJS nº1 Gijón, de 20 de febrero de 2019 (núm. 61/2019) (F.J 3º, epígrafe $3^{\circ}$ párrafo segundo), STSJ Asturias de 25 de julio de 2019 (núm. 1818/2019; rec. 1143/2019) (F.J $39^{\circ}$ ) y SJT Madrid de 27 de noviembre de 2019 (F.J $\left.4^{\circ}\right)$

8. Entre la doctrina también encontramos reflexiones en esta línea. Cruz Villalón, J. (2018). E concepto de trabajador subordinado frente a las nuevas formas de empleo. Revista de Derecho Social, (núm. 83), págs. 38 y 39 .

9. Como así establecen SJS n³9 de Madrid, de 3 de septiembre de 2018 (núm. 284/2018; rec 1353/2017) (F.J. 5º ordinal 2), SJS nº1 de Salamanca, de 14 de junio de 2019 (núm. 215/2019) (F.J. 4, duodécimo párrafo)

10. SJS n³9 de Madrid, de 3 de septiembre de 2018 (núm. 284/2018; rec. 1353/2017) (F.J. $5^{\circ}$ ordinal 4). del servicio ${ }^{11}$. EI TS coincide en su reciente sentencia con esta tendencia mayoritaria y desarrolla argumentos prácticamente idénticos. En el fundamento jurídico $19^{\circ}$, ordinal $2^{\circ}$, el Alto Tribunal establece que el repartidor se limitaba a recoger el pedido y llevarlo al domicilio. Dicha tarea estaba sujeta a reglas precisas impuestas por la empresa. Más aún, de forma contunde concluye que la autonomía del repartidor es muy limitada, alcanzando únicamente cuestiones secundarias como elegir la ruta o el medio de transporte ${ }^{12}$.

Un nuevo indicio a tener en cuenta es el relativo a si dichas empresas llevan a cabo un seguimiento y control de la prestación del servicio. Podemos encontrar sentencias previas que ya venían afirmando que el modelo de negocio del trabajo en plataformas permite a la empresa controlar las actuaciones del repartidor ${ }^{13}$. E TS hace suya esta línea, afirmando, en el fundamento jurídico $21^{\circ}$, que la empresa ha establecido medios para controlar, no ya únicamente el resultado, sino también la actividad. Sobre este punto, el TS afirma que el uso de la geolocalización por GPS "es también un indicio relevante de dependencia", como expresamente afirma en el ordinal $1^{\circ}$ del fundamento jurídico $19^{\circ}$, poniendo en valor una idea que había quedado prácticamente olvidada entre la doctrina judicial ${ }^{14}$.

Antes de finalizar con el estudio de la nota de subordinación, es necesario examinar los aspectos relativos al poder disciplinario. Varias sentencias incluían la ausencia de poder disciplinario en su fundamentación jurídica para declarar la no laboralidad de la relación contractual ${ }^{15}$

11. Respecto a las resoluciones administrativas, Acta ITSS de Valencia sobre Deliveroo de diciembre de 2017, citada en Beltrán de Heredia Ruiz, I. (2018). Economía de las plataformas (platform economy) y contrato de trabajo. XXIX Jornades Catalanes de Dret Social. Pág. 67. Respecto a las sentencias, he de destacar, entre todas ellas, la SJS n³1 de Barcelona, de 11 de junio de 2019 (núm. 193/2019) (F.J. 6º), por su exhaustivo y completa argumentación sobre este punto, así como la STSJ Asturias de 25 de julio de 2019 (núm. 1818/2019; rec. 1143/2019) (F.J. $4^{\circ}$ ).

12. El tema de la ruta causó cierta controversia entre los tribunales de rango inferior. A favor del carácter secundario de la ruta SJS n² de Zaragoza, de 27 de abril de 2020 (núm. 123/2020 rec. 521/2018) (F.J. $7^{\circ}$, cuarto párrafo) y en contra, SJS nº 1 de Salamanca, de 14 de junio de 2019 (núm. 215/2019) (F.J. $4^{\circ}$, duodécimo párrafo), STSJ Madrid de 19 de septiembre de 2019 (núm. 715/2019; rec. 195/2019) (F.J. $3^{\circ}$ )

13. Idea introducida en la SJS nº1 Gijón, de 20 de febrero de 2019 (núm. 61/2019) (F.J. 6 , ordinal 3 , tercer párrafo) y reiterada en la STSJ de Asturias (F.J. $4^{\circ}$ )

14. Únicamente la STSJ Asturias de 25 de julio de 2019 (núm. 1818/2019; rec. 1143/2019) (F.J. $4^{\circ}$ ) defendió que el GPS constituía un mecanismo de control, recordando la SAN, Sala de lo Social, de 6 febrero 2019 (proc. 318/2018)

15. Entre ellas, SJS n²4 de Barcelona, de 29 de mayo de 2019 (núm. 205/2019) (F.J. 4º), SJS n¹7 de Madrid, de 11 de enero de 2019 (núm. 12/2019) (F.J. 2). 
Frente a todo ello, el TS es bastante expreso al valorar esta cuestión, afirmando, en su fundamento jurídico $19^{\circ}$ ordinal $5^{\circ}$, que algunas de las causas de resolución del contrato entre empresa y repartidor "son trasunto literal" de las causas de despido del art. 54 LET. Teniendo esto en cuenta, es interesante resaltar no solo que la anterior tesis haya sido previamente expuesta por tribunales de menor rango ${ }^{16}$, sino que, además, dichos órganos han desarrollado argumentos más extensos sobre el poder disciplinario. Por ejemplo, la idea de que el sistema de incentivos usado por la empresa y su efecto penalizador es propio de una relación laboral ${ }^{17}$.

Es necesario anotar que precisamente estos últimos indicios analizados, el poder de control mediante un sistema de geolocalización y el poder disciplinario, fueron igualmente empleadas por la Cour de cassation francesa -equivalente a nuestro TS- para defender la existencia de la subordinación y, por ende, la relación laboral entre una empresa de reparto urbano y el rider ${ }^{18}$

\subsection{Indicios de ajenidad: sobre para quién trabaja el repartidor}

Uno de los debates más controvertidos y, a su vez, más clarificadores ha sido el referente a cuáles sean realmente los medios de producción necesarios para desarrollar est tipo de actividad. Previamente he de señalar que, en este caso, la frontera entre indicio de ajenidad o de subordinación es especialmente difusa. Muchas sentencias estudian la cuestión de los medios aportados como un indicio de la ajenidad. Tampoco les falta razón a las voces que afirman que la propiedad de los medios influye en el grado de subordinación. Personalmente, coincidiendo con el criterio del TS, considero que es más correcto entender la propiedad de los medios de producción como un indicio de ajenidad -concretamente, ajenidad en los medios-. No obstante, sería ingenuo obviar su posible influencia en la dependencia.

Ciertas sentencias que abogan por la no laboralidad de la relación consideran como una importante seña de autonomía el hecho de que los repartidores aporten, a su juicio los principales elementos para llevar a cabo la actividad (móvil y bicicleta o motocicleta) ${ }^{19}$.

16. Puesto de manifiesto por primera vez en la SJS nº1 Gijón, de 20 de febrero de 2019 (núm 61/2019) (F.J.31, ordinal 3, cuarto párrafo) y reiterado en STSJ Madrid de 27 de noviembre de 2019 (núm.1155/2019; rec. 588/2019) (F.J. 40).

17. Como así afirma SJS n³1 de Barcelona, de 11 de junio de 2019 (núm. 193/2019) (F.J. 3º).

18. Arrêt n¹737 du 28 novembre 2018 (17-20.079) - Cour de cassation - Chambre sociale.

19. Entre otras sentencias SJS nº39 de Madrid, de 3 de septiembre de 2018 (núm. 284/2018; rec. 1353/2017) (F.J. 5º, ordinal 5), SJS nº1 de Salamanca, de 14 de junio de 2019 (núm. 215/2019) (F.J. $4^{\circ}$, duodécimo párrafo).
No obstante, esta idea ha sido rebatida por prácticamente todas las sentencias de rango inferior que declaraban la laboralidad ${ }^{20}$. En todos ellos se sostenía que, cualitativamente, el medio verdaderamente fundamental y causa del éxito de la empresa es la aplicación informática (junto con la marca, que se analizará posteriormente). Y en esta línea, que, cuantitativamente, el valor de la aplicación es muy superior al que puede alcanzar un móvil y una bicicleta o motocicleta. Según esto, sería correcto concluir que la aplicación informática, propiedad de la empresa, es el verdadero medio de producción y que, por tanto, lo aportado por el repartidor es de carácter secundario, esto es, meras herramientas.

Nuestro Alto Tribunal, por su parte, también concluye que existe ajenidad en los medios reiterando la distinción anteriormente expuesta con términos prácticamente idénticos, como así podemos comprobar en el fundamento jurídico $20^{\circ}$, ordinal $4^{\circ}$. Por un lado alude a la importancia económica de la plataforma informática en relación con los medios aportados por el repartidor; $\mathrm{Y}$, por otro lado, remarca que el medio de producción esencial es la propia plataforma.

No es la primera vez que se expone esta tesis en la sala cuarta del TS. Recordemos ahora la STS de 26 de febrero de 1986 (núm. 263/1986). En dicho pronunciamiento, relativo al conocido como caso mensajeros, el TS considera como indicio de laboralidad el carácter auxiliar y secundario de los medios aportados por los trabajadores ${ }^{21}$. Esta tesis casa perfectamente, 34 años más tarde, con las plataformas de reparto urbano

Junto a la importancia de la aplicación, se ha puesto de manifiesto la relevancia de la marca. Varias sentencias, tanto de Juzgados de lo Social como de Tribunales Superiores de Justicia, defendían que el éxito de estas empresas se basa en el uso de una aplicación pero también en la explotación de una marca, propiedad de la empresa ${ }^{22}$. Sobre este punto, la aportación del TS podría calificarse como demasiado escueta. En la reciente sentencia el Alto Tribunal, en el ordinal $4^{\circ}$ del fundamento jurídico $20^{\circ}$, simplemente afirma que el rider "realizaba su actividad bajo una marca ajena", pero no continúa desarrollando dicha idea.

20. Las argumentaciones más exhaustivas se pueden encontrar en la SJS n³3 de Madrid, de 11 de febrero de 2019 (núm. 53/2019) (F.J. 12º, tercer párrafo), STSJ Asturias de 25 de julio de 2019 (núm. 1818/2019; rec. 1143/2019) (F.J. 4º), SJS nº19 de Madrid, de 22 de julio de 2019 (núm. 188/2019) (F.J. 5 ${ }^{\circ}$, segundo párrafo).

21. En posteriores litigios, el TS ha continuado afirmando la laboralidad de ciertas relaciones contractuales en las que el trabajador aportaba medios propios; Entre otras, STS 5 de noviembre de 1993 (rec. 708/1992) sobre transportistas con vehículo propio. Más actuales, las STS 16 de noviembre de 2017 (núm. 902/2017; rec. 2806/2015) y SSTS 24 de enero de 2018 (núm.44/2018; rec. 3394/2015) y (núm.45/2018; rec.3595/2015), STS de 8 de febrero de 2018 (núm. 127/2018; rec. 3389/2015).

22. Como puede comprobarse en SJS n³3 de Madrid, de 11 de febrero de 2019 (núm. 53/2019) (F.J. 12 , tercer párrafo), STSJ Asturias de 25 de julio de 2019 (núm. 1818/2019; rec. 1143/2019) (F.J 4º), SJS n³1 de Barcelona, de 11 de junio de 2019 (núm. 193/2019) (F.J. 3º) 
Ahora sí, analizaremos los indicios de ajenidad desde las tradicionales clasificaciones de este elemento: ajenidad en los frutos, ajenidad en los riesgos y ajenidad en el mercado.

Respecto a la ajenidad en los frutos, las sentencias de rango inferior que declaran la laboralidad han mantenido una postura casi unánime. Los frutos del servicio prestado provienen tanto del precio pagado por el cliente como de la cantidad abonada por los establecimientos $^{23}$. Teniendo esto en cuenta, la empresa hace suyo el resultado, es de su propiedad ${ }^{24}$. O lo que es lo mismo, el trabajador no participa en el beneficio empresarial $^{25}$. Nuevamente, el TS confirma la existencia de la ajenidad en los frutos, empleando para ello términos muy parecidos a los expuestos previamente. En virtud del ordinal $3^{\circ}$ del fundamento jurídico $20^{\circ}$ de la reciente sentencia, la plataforma "se apropia de manera directa del resultado", haciendo suyos los frutos del mismo. Hemos de destacar que el TS no emplea más de dos líneas en justificar este extremo, lo que puede resultar escaso en comparación con el desarrollo llevado a cabo por tribunales inferiores. En contraposición, donde sí centra el Alto Tribunal su atención es en el hecho de que el repartidor no pueda intervenir en las cuestiones relativas al precio y condiciones de pago, idea que repite en varios fundamentos jurídicos.

La ajenidad en los riesgos supuso una alta conflictividad entre los juzgados inferiores Gran parte de las sentencias que establecían la extralaboralidad de la relación afirmaron que el repartidor corría el riesgo y ventura del negocio ${ }^{26}$. En contraposición, prácticamente la totalidad de sentencias que abogaban por la laboralidad incluían en su argumentación referencias a la ajenidad en los riesgos ${ }^{27}$.

Para alcanzar una visión completa sobre ajenidad en los riesgos es necesario indaga sobre qué consecuencias tiene para el repartidor las posibles vicisitudes de la prestación del servicio. Sobre el particular, conviene recordar, siquiera en líneas muy generales, que el crédito salarial nace con la correcta prestación del servicio, independientemente de

23. Esta afirmación, bastante clarificadora, es puesta de manifiesto por la SJS n³1 de Barcelona de 11 de junio de 2019 (núm. 193/2019) (F.J. 3º)

24. Entre otras SJS n³3 de Madrid, de 11 de febrero de 2019 (núm. 53/2019) (F.J. 13º, tercer párrafo), STSJ Asturias de 25 de julio de 2019 (núm. 1818/2019; rec. 1143/2019) (F.J. 34º), STS Madrid de 27 de noviembre de 2019 (núm.1155/2019; rec. 588/2019) (F.J. $5^{\circ}$, último párrafo)

25. Argumento incluida en SJS nº de Valencia, de 1 de junio de 2018 (núm. 244/2018) (F.J. $2^{\circ}$ ), SJS n³ de Barcelona, de 18 de noviembre de 2019 (núm. 325/2019) (F.J. 4º, ordinal 23).

26. A modo de ejemplo, SJS n³9 de Madrid, de 3 de septiembre de 2018 (núm. 284/2018; rec 1353/2017) (F.J.5 , ordinal 4), SJS n¹ de Salamanca, de 14 de junio de 2019 (núm. 215/2019) (F.J 4º, párrafo duodécimo SJS nº17 de Madrid, de 11 de enero de 2019 (núm. 12/2019) (F.J. 2º)

27. Entre muchas otras, SJS nº de Valencia, de 1 de junio de 2018 (núm. 244/2018) (F.J. $2^{\circ}$ ), SJS nº1 Gijón, de 20 de febrero de 2019 (núm. 61/2019) (F.J 3º, ordinal 3º), SJS n³1 de Barcelona, de 11 de junio de 2019 (núm. 193/2019) (F.J. 3º). buen fin del negocio ${ }^{28}$. Pues bien, en nuestro caso, por un lado, queda demostrado que, si el reparto no se desarrolla, el rider no cobra dicho servicio. Pero esto no implica que el repartidor corra el riesgo y ventura del negocio; sino que dicha consecuencia deriva de la tipología de retribución por unidad de obra, que encaja sin problema en los amplios márgenes del art. 26 LET. Entre los pronunciamientos de rango inferior ya se había puesto de manifiesto esta idea ${ }^{29}$. Por su parte, nuestro Alto Tribunal, para defender la existencia de ajenidad en los riesgos, emplea precisamente esta reflexión. En palabras del TS: "el hecho de no cobrar por el servicio si éste no llega a materializarse es consecuencia obligada de la retribución por unidad de obra", sin que ello implique que el repartidor asuma "el riesgo y ventura" (véase el fundamento jurídico $20^{\circ}$ ordinal $2^{\circ}$ ). El propio Tribunal trae a coalición su sentencia de 15 de octubre de 2001 (rec. 2283/2000) donde afirma que cuando se pacta que el trabajador no perciba comisión cuando la operación no se realice no supone que este asuma la responsabilidad del buen fin de las operaciones.

Por otro lado, hemos de reflexionar sobre las consecuencias, no ya de no realizar el servicio, sino de desarrollarlo de forma negligente. Una de las primeras resoluciones de suplicación sobre el tema incluye un interesante argumento en esta línea: el riesgo que corre el repartidor no es otro que el de responder frente a situaciones donde no haya actuado diligentemente, pero esta responsabilidad "resulta plenamente compatible con el trabajo asalariado" en virtud de "los párrafos a) y c) del art. 5 LET"30 y no puede ser confundida con la responsabilidad empresarial de un trabajador autónomo. La propia resolución antes mencionada STS de 26 de febrero de 1986 (núm. 263/1986) ya incluía esta idea. Teniendo esto en cuenta, llegamos a uno de los puntos más controvertidos. En la sentencia objeto de estudio, el Alto Tribunal llega a afirmar que el hecho de asumir los daños o pérdidas de los productos durante el transporte "es un indicio contrario a la existencia de una relación laboral" (véase fundamento jurídico $20^{\circ}$ ordinal $2^{\circ}$ ). Con este argumento, el TS se aparta de lo expuesto en el indicado pronunciamiento de 1986, lo que supone una llamativa excepción puesto que en la mayoría de los casos este Tribunal ha seguido la línea que previamente había marcado.

Finalmente, y en relación con la ajenidad de los frutos y de los riesgos, surge la idea del riesgo-lucro especial. Debemos subrayar que solo alguna sentencia de los órganos inferiores había incidido sobre esta idea, afirmando que en el trabajo en plataformas no existe

28. Costa Reyes, A. (2004) El crédito salarial, CES-A, págs. 41 y sgs.

29. Argumento incluido en STSJ Madrid de 27 de noviembre de 2019 (núm.1155/2019; rec. 588/2019) (F.J. $36^{\circ}$ ) SJS n5 de Valencia, de 10 de junio de 2019 (núm. 197/2019; rec. 371/2018 (F.J. $2^{\circ}$ ), SJS Social nº19 de Madrid, de 22 de julio de 2019 (núm. 188/2019) (F.J. $4^{\circ}$, último párrafo)

30. Esta importante distinción la establece la STSJ Madrid de 27 de noviembre de 2019 (núm.1155/2019; rec. 588/2019) (F.J. 37º). 
ningún lucro especial ${ }^{31}$. A pesar de la escasa atención que esta cuestión había recibido, el TS en su reciente sentencia aborda esta idea afirmando expresamente que no puede considerarse que concurra "el binomio riesgo-lucro especial" propia del trabajo autónomo.

Tras todo lo anterior, quedaría por analizar la ajenidad en el mercado. En líneas generales, este indicio es el que menos confrontación argumental ha provocado. Siguiendo los argumentos esgrimidos por las resoluciones de los tribunales inferiores podemos entender que existe ajenidad en el mercado puesto que es la empresa quien contacta con los establecimientos, capta clientes, se publicita y, en general, mantiene relaciones con el propio mercado. En términos estrictamente jurídicos, concluían, "no son los repartidores parte en los negocios jurídicos existentes con los restaurantes y con los destinatarios de comida"32. Por su parte, el TS afirma expresamente que la empresa es la encargada de tomar las decisiones empresariales. Aún más, expone que tanto los consumidores como los establecimientos son clientes de la plataforma, no del repartidor. Dichas ideas, recogidas en el ordinal $1^{\circ}$ del fundamento jurídico $20^{\circ}$, son suficientes para demostrar la existencia de ajenidad en el mercado. No obstante, el TS no menciona dicho indicio de forma expresa.

Muy relacionado con lo anterior, un nuevo indicio de laboralidad está adquiriendo cada vez más protagonismo: la ajenidad en la información. La empresa posee la información relativa al establecimiento y al cliente, que se convierte en esencial para presta el servicio. El repartidor no posee información alguna sobre establecimientos ni clientes, hasta el mismo momento de realizar el servicio ${ }^{33}$. Aunque sólo algunos Juzgados de lo Social han centrado su atención sobre este hecho, el TS lo incluye entre los indicios favorables a la existencia de una relación laboral. Eso sí, de nuevo sin hacer referencia expresa al término "ajenidad en la información" como se puede observar en el fundamento jurídico $19^{\circ}$ ordinal $6^{\circ}$

\section{Algunas conclusiones sobre la sentencia del Tribunal Supremo}

El Alto Tribunal, mediante una ponderación de indicios (extraídos tras un análisis exhaustivo sobre el modelo de negocio, en general, y sobre las relaciones entre plataforma y repartidores, en particular), consigue demostrar la existencia de las notas de ajenidad y subordinación y, consiguientemente, la naturaleza laboral de la relación.

31. Concretamente SJS n³1 de Barcelona, de 11 de junio de 2019 (núm. 193/2019) (F.J. $3^{\circ}$ ).

32. Entrecomillado de SJS nº19 de Madrid, de 22 de julio de 2019 (núm. 188/2019) (F.J. 50 segundo párrafo) aunque también se repite este argumento en SJS n³3 de Madrid, de 11 de febrero de 2019 (núm. 53/2019) (F.J. 13ํ), SJS nº de Valencia, de 1 de junio de 2018 (núm. 244/2018) (F.J. $2^{\circ}$ ); STSJ Asturias de 25 de julio de 2019 (núm. 1818/2019; rec. 1143/2019) (F.J. $5^{\circ}$, último párrafo)

33. Argumento expresamente recogido en SJS n5 de Valencia, de 10 de junio de 2019 (núm. 197/2019; rec. 371/2018) (F.J. 2º), SJS nº19 de Madrid, de 22 de julio de 2019 (núm. 188/2019) (F.J. $6^{\circ}$ ).
Como se ha podido comprobar a lo largo de este artículo, el TS, a la hora de demostrar la naturaleza laboral de la relación entre repartidores y plataformas, expone reflexiones que previamente habían sido puestas de manifiesto por órganos de menor rango, así como tribunales foráneos. Evidentemente, la coincidencia no es completa. EI TS aborda algunas cuestiones que prácticamente no habían recibido atención por otros órganos, como la remuneración del tiempo de espera o el hecho de que la empresa ponga a disposición del repartidor una tarjeta de crédito. De igual modo, el TS no muestra demasiada atención a aspectos que previamente habían sido estudiados con detenimiento. Por ejemplo, la ajenidad en el mercado o en la marca. No obstante, estos casos no son más que excepciones que confirman la regla puesto que, reiteramos, la coincidencia es prácticamente total. Esta identidad de conclusiones demuestra, a nuestro entender, que ya existían los elementos para demostrar la naturaleza laboral de estas relaciones contractuales, cuestionando as posiciones que defienden una postura rupturista en el alcance de este tipo de trabajo.

Un aspecto especialmente interesante sobre la actuación del Alto Tribunal es que, mediante la labor de ponderación desarrollada a lo largo de la presente sentencia, el TS lleva a cabo una interpretación de los indicios de laboralidad a la luz de las novedades de trabajo en plataformas ${ }^{34}$. En estrecha relación con la idea anterior, es necesario recordar que las tensiones causadas por el trabajo en plataformas no son extrañas al Derecho del Trabajo. Desde el nacimiento de nuestra disciplina, tal cual la conocemos hoy en día, han surgido innumerables debates sobre la naturaleza jurídica de relaciones contractuales -siendo los mencionados en este estudio una pequeña muestra del total-. Ante ello, nuestro Alto Tribunal ha ido resolviendo, caso por caso, gran parte de estas tensiones.

En resumen, la sentencia del TS abordada por este estudio, al igual que hizo su homólogo francés, no solo constata que la relación contractual entre repartidor y empresa es de naturaleza laboral; sino que, mediante la actualización de los indicios de laboralidad demuestra que nuestro actual marco laboral es capaz de responder a las exigencias nacidas a raíz de nuevas formas de trabajo. Una vez más es posible afirmar que el sistema indiciario es un instrumento lo suficientemente versátil como para adaptarse a las nuevas formas de trabajo, sin necesidad de rechazar los conceptos la ajenidad y la subordinación sobre los que descansa nuestra disciplina

Aunque esta sentencia sea considerada como la tan esperada solución para el presente conflicto, no faltan voces que reclaman alguna intervención normativa expresa. Por un

34. Desde la doctrina encontramos reflexiones que ya venían apuntando en esta dirección. Así, Navarro Nieto ha afirmado que las notas de ajenidad y subordinación siguen siendo factibles para identificar la naturaleza laboral en el trabajo en plataformas "aunque ello requiera la adaptación de los indicios de laboralidad a la economía digital”. Navarro Nieto, F. (2018). El debate sobre la laboralidad de la prestación de servicios en la economía digital. Diario La Ley, (núm. 9225), pág. 9. 
lado, en aras de aumentar la seguridad jurídica, una posible iniciativa podría ser recoger en un texto normativo los avances llevados a cabo por la jurisprudencia ${ }^{35}$. Esta opción de política legislativa no es desconocida en nuestro ordenamiento jurídico puesto que ya fue empleada, por citar algún caso, en la redacción del art. 43 LET sobre cesión ilegal de trabajadores. No obstante, en mi opinión, hemos de ser cautos con esta propuesta puesto que, si bien podría aumentar la seguridad jurídica, en contraposición, también podría reducir la versatilidad y adaptabilidad propia del análisis indiciario -siendo este un carácter muy valorable, como se argumentó supra-.

Por otro lado, buscando precisamente dar respuesta a las peculiaridades de este tipo de trabajo en plataformas, venía reclamándose la consideración de relación laboral de carácter especial, tanto desde una parte de la doctrina como desde pronunciamientos judiciales de inferior rango ${ }^{36}$. En este caso, se reglamentaría una regulación específica, evitando así la aplicación en bloque del ordenamiento laboral. En mi opinión, mediante esta solución, la adaptación a dichas singularidades tendría un alto coste en relación con los derechos de los trabajadores puesto que mediante esa regulación especial se podría evitar la aplicación de ciertos preceptos del ordenamiento laboral. Por esta razón, y precisamente por las particularidades de estas nuevas formas de trabajo y su encaje en el ordenamiento, considero que la negociación colectiva puede ser considerada como el instrumento idóneo para abordar esta problemática, puesto que, además de responder a dichas singularidades, permite mantener un enfoque tuitivo respecto al trabajador asalariado, al contrario de lo que ocurre con las relaciones laborales de carácter especial ${ }^{13}$.

35. Esto es lo que precisamente ha ocurrido en Estados Unidos. Como analiza Todolí Signes, la nueva ley del Estado de California sobre el concepto de trabajador "se limita a incorporar los criterios judiciales seguidos para la identificación de un asalariado". Todolí Signes, A. (2020). El ámbito subjetivo de aplicación del Estatuto de los Trabajadores ante las nuevas formas de trabajo: la nueva ley de California (AB5). Trabajo y derecho: nueva revista de actualidad y relaciones laborales, (núm. 66).

36. Respecto a la doctrina, Todolí Signes, A. (2015). "El impacto de la "Uber Economy" en las relaciones laborales: los efectos de las plataformas virtuales en el contrato de trabajo. IUSLabor, núm. 3/2015, pág. 21. Respecto a la doctrina judicial, la SJS nº33 de Madrid (F.J. 16º, segundo párrafo)

37. Para Serrano Olivares, las especialidades de esta forma de trabajo pueden ser "recogidas y abordadas a través de la negociación colectiva". Serrano Olivares, R. (2017). Nuevas formas de organización empresarial: economía colaborativa, -o mejor economía digital a demanda-, trabajo 3.0 y laboralidad. En Economía colaborativa y trabajo en plataforma: realidades y desafíos. Editoria Bomarzo., pág. 46. Más en profundidad, Costa Reyes considera que, sobre la base del contrato a tiempo parcial y teniendo en cuenta que el tiempo de espera también debe considerarse como tiempo de trabajo, la negociación colectiva puede ser de utilidad para flexibilizar el marco jurídico aplicable, estableciendo una remuneración distinta entre la prestación efectiva del servicio y el tiempo de espera Costa Reyes, A. (2019). Economía colaborativa, plataformas digitales y Derecho del Trabajo. En AAVV Gonsálbez Pequeño, Dir.), Régimen jurídico del consumo colaborativo. Aranzadi, págs. 261-307.
Por concluir, resulta cuando menos paradójico que, a raíz de una problemática específica sobre un concreto grupo de trabajadores, se hayan llegado a cuestionar los propios cimientos de nuestra disciplina. Por su origen histórico, así como, por su singular objeto de estudio, las tensiones sobre el ámbito de aplicación del Derecho del Trabajo se encuentran en su propio ADN. El jurista del trabajo, ante discusiones como la que protagoniza este artículo, no debe echarse las manos a la cabeza, sino ponerse manos a la obra. 


\section{Bibliografía}

Alonso Olea, M. (1994). Introducción al Derecho del Trabajo. Civitas.

Costa Reyes, A. (2004) El crédito salarial, CES-A.

Costa Reyes, A. (2019). Economía colaborativa, plataformas digitales y Derecho del Trabajo. En AAVV (Gonsálbez Pequeño, Dir.), Régimen jurídico del consumo colaborativo. Aranzadi.

Cruz Villalón, J. (2018). El concepto de trabajador subordinado frente a las nuevas formas de empleo. Revista de Derecho Social, (núm. 83).

Cruz Villalón, J. (2018). Las transformaciones de las relaciones laborales ante la digitalización de la economía". Temas laborales, núm. 138/2018, págs.

De Las Heras García, A y Lanzadera Arencibia, E. (2019). El trabajo en plataformas digitales, puro... y duro. Un análisis desde los factores de riesgo laboral. Revista de Trabajo y Seguridad Social, CEF, número extraordinario 2019.

De Stefano, V. (2016) The rise of the «just-in-time workforde»: On-demand work, crowdwork and labour protection in the "gig-economy»; Conditions of work and employ ment, ILO (no. 71).

Gines y Fabrelals, A. (2016). Crowdsourcing sites y nuevas formas de trabajo. El caso de Amazon Mechanical Turk. Revista Derecho Social y Empresa; núm. 6, diciembre.

Gorelli Hernández, J. (2019). Indicios de la moralidad en el trabajo a través de plataformas (crowdsourcing offline)". Revista de Derecho Social, núm. 86.

Navarro Nieto, F. (2018). El debate sobre la laboralidad de la prestación de servicios en la economía digital. Diario La Ley, (núm. 9225).

Serrano Olivares, R. (2017). Nuevas formas de organización empresarial: economía colaborativa, -o mejor economía digital a demanda-, trabajo 3.0 y laboralidad. En Economía colaborativa y trabajo en plataforma: realidades y desafíos. Editorial Bomarzo.

Todolí Signes, A. (2015). “El impacto de la “Uber Economy” en las relaciones laborales: los efectos de las plataformas virtuales en el contrato de trabajo. IUSLabor, núm. 3/2015, pág. 21.

Todolí Signes, A. (2020). El ámbito subjetivo de aplicación del Estatuto de los Trabajadores ante las nuevas formas de trabajo: la nueva ley de California (AB5). Trabajo y derecho: nueva revista de actualidad y relaciones laborales, (núm. 66).

\section{Anexo jurisprudencial}

Arrêt n¹737 du 28 novembre 2018 (17-20.079) - Cour de cassation - Chambre sociale.

Sentencia del Tribunal de Justicia de la Unión Europea de 20 de diciembre de 2017, asunto $\mathrm{C}-434 / 15$.

Sentencia del Tribunal Supremo (Sala cuarta), de 25 de septiembre de 2020 (núm. 805/2020; 4746/2019).

STS de 15 de octubre de 2001 (rec. 2283/2000).

STS de 26 de febrero de 1986 (núm. 263/1986).

STS 16 de noviembre de 2017(núm. 902/2017; rec. 2806/2015).

SSTS de 24 de enero de 2018 (núm.44/2018; rec. 3394/2015).

STS de 24 de enero de 2018 (núm.45/2018; rec.3595/2015).

STS de 8 de febrero de 2018 (núm. 127/2018; rec. 3389/2015).

Sentencia del Tribunal Superior de Justicia (STSJ) de Asturias de 25 de julio de 2019 (núm. 1818/2019; rec. 1143/2019).

STSJ de Madrid de 19 de septiembre de 2019 (núm. 715/2019; rec. 195/2019).

STSJ de Madrid de 27 de noviembre de 2019 (núm.1155/2019; rec. 588/2019).

STSJ de Madrid de 18 de diciembre de 2019 (núm. 1223/2019; rec.714/2019).

STSJ de Madrid de 17 de enero de 2020 (núm. 40/2020; rec. 1323/2019

STSJ de Madrid de 3 de febrero de 2020 (núm. 68/2020; rec. 749/2019).

STSJ de Castilla y León (Valladolid) de 17 de febrero de 2020 (rec. 2253/2019)

STSJ de Cataluña de 21 de febrero de 2020 (núm. 1034/2020; rec. 5613/2019).

Sentencia Juzgado de lo Social (SJS) nº de Valencia, de 1 de junio de 2018 (núm. 244/2018).

SJS n³9 de Madrid, de 3 de septiembre de 2018 (núm. 284/2018; rec. 1353/2017).

SJS nº17 de Madrid, de 11 de enero de 2019 (núm. 12/2019).

SJS n³3 de Madrid, de 11 de febrero de 2019 (núm. 53/2019).

SJS n¹ Gijón, de 20 de febrero de 2019 (núm. 61/2019).

SJS n²4 de Barcelona, de 29 de mayo de 2019 (núm. 205/2019). 
SJS n5 de Valencia, de 10 de junio de 2019 (núm. 197/2019; rec. 371/2018).

SJS n³1 de Barcelona, de 11 de junio de 2019 (núm. 193/2019; rec. 662/2017)

SJS n¹ de Salamanca, de 14 de junio de 2019 (núm. 215/2019).

SJS nº19 de Madrid, de 22 de julio de 2019 (núm. 188/2019)

SJS n³ de Barcelona, de 18 de noviembre de 2019 (núm. 325/2019).

SJS n² de Zaragoza, de 27 de abril de 2020 (núm. 123/2020; rec. 512/2018) 